
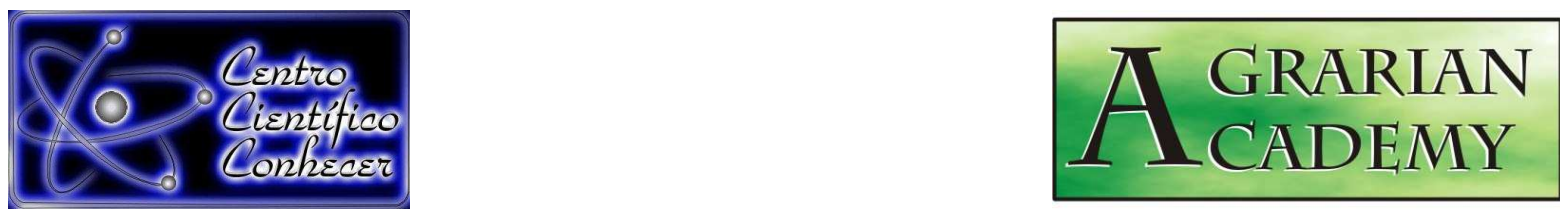

\title{
POTENCIAL CITOTÓXICO E GENOTÓXICO DA ÁGUA DE RIOS DO MUNICÍPIO DE CARLINDA, MATO GROSSO, BRASIL, POR MEIO DO TESTE Allium cepa L.
}

Kelli Évelin Müller Zortéa ${ }^{1}$; Jociele dos Santos Lemes ${ }^{1}$; Maiara Nascimento². Ana Paula Tafarelo'; Ana Aparecida Bandini Rossi ${ }^{3}$.

1. Biólogas, Universidade do Estado do Mato Grosso - UNEMAT, Campus de Alta Floresta, MT, Brasil.E-mail: kellimuller@hotmail.com

2. Graduada em Farmácia pela Universidade Federal do Estado de Mato Grosso, Campus Sinop - MT, Brasil.

3. Doutora em Genética e Melhoramento. Laboratório de Genética vegetal e Biologia Molecular. Professora da Faculdade de Ciências Biológicas e Agrárias, PPGBioAgro,

PMGP e PPG-Bionorte. UNEMAT, Campus de Alta Floresta, MT, Brasil.

Recebido em: 01/07/2015 - Aprovado em: 31/07/2015 - Publicado em: 21/08/2015

\section{RESUMO}

A atividade garimpeira gera inúmeros impactos ambientais como: assoreamento, erosão e contaminação por substâncias químicas, sendo a mais grave por mercúrio. Estudos de monitoramento ambiental têm mostrado efeitos danosos das atividades humanas no ambiente natural. O Teste de Allium cepa já foi utilizado para testar inúmeras substâncias e tem como vantagens: baixo custo, facilidade de execução e análise e poder ser realizado in vivo. Esse trabalho objetivou a realização de análises citotóxicas e genotóxicas das águas de rios de Carlinda-MT, com histórico de garimpo, através do teste de $A$. cepa. Para realização desse trabalho, os bulbos da cebola foram expostos a cinco tratamentos diferentes, mais um controle negativo em água destilada. Foram analisadas 2.000 células por tratamento. O maior Indice Mitótico (IM) ocorreu no tratamento do rio Buritis $(28,65 \%)$ e o menor no controle negativo (10,65\%). Teles Pires (IM 13,45\%) foi o que se aproximou mais do controle. Se comparado com o controle negativo, os demais tratamentos apresentaram aumento médio no IM. Foram observados dois tipos diferentes de anormalidades cromossômicas: ponte de cromatina $(18,46 \%)$ e cromossomos isolados $(81,54 \%)$, sendo a segunda a com maior incidência. $O$ teste $A$. cepa demonstrou que há algum tipo de alteração nos tratamentos Carlinda, Nacional, São José e Buritis devido ao aumento do IM e aparecimento de aberrações cromossômicas. O rio Teles Pires não apresentou potencial citogenotóxico. Sugere-se que mais estudos sejam realizados nas áreas.

PALAVRAS-CHAVE: Bioindicador, Índice Mitótico, Meio Ambiente.

\section{CYTOTOXIC AND GENOTOXIC POTENTIAL OF WATER OF RIVERS IN THE MUNICIPALITY OF CARLINDA, MATO GROSSO, BRAZIL, BY MEANS OF THE TEST Allium cepa L.}

\begin{abstract}
Gold mining activity has numerous environmental impacts including silting, erosion, and chemical contamination of surface water, soils, and groundwater. Studies
\end{abstract}


monitoring long-term impacts have proven the harmful effects of mining on natural environments. The Allium cepa test is low-cost procedure which is simple to execute and analyze, with the further advantage that it may be realized in vivo. This study used the $A$. cepa test to perform analyses of cytotoxicity and genotoxicity of surface water in rivers with a history of gold mining activity in the municipality of Carlinda, Mato Grosso, Brazil. Onion bulbs were exposed to five different treatments in addition to a negative control using distilled water. In each treatment, 2.000 cells were analyzed. The greatest mitotic index (MI) was recorded in the Buritis river sample $(28,65 \%)$, and the lowest in our negative control $(10,65 \%)$. The Teles Pires river sample (MI 13,45\%) was closest to our control. Relative to the negative control, the five treatments showed moderate $\mathrm{Ml}$ increases. Two types of chromosomal abnormalities were observed: chromatin bridge (18,46\%) and isolated chromosomes $(81,54 \%)$, the latter with greater incidence. The $A$. cepa test demonstrates that the treatments of the Carlinda, Nacional, São José, and Buritis watercourses all show alteration given the elevated $\mathrm{Ml}$ and appearance of chromosome aberrations. The Teles Pires river treatment did not present cytogenotoxicity. We suggest further study in the area.

KEYWORDS: Bioindicator, Mitotic Index, Environment.

\section{INTRODUÇÃO}

Durante toda a década de 80 , a região norte do estado de Mato Grosso foi alvo da exploração garimpeira, que mudou completamente o perfil agropecuário traçado originalmente pelo projeto de colonização de alguns municípios, como por exemplo, o de Carlinda, tornando esta região em um polo regional de atividades ligadas ao garimpo em muito pouco tempo (CUNHA et al., 2002).

As atividades garimpeiras geram inúmeros impactos ambientais, sendo estes físicos e biológicos. Os impactos biológicos tem início na alteração da qualidade da água por intermédio do assoreamento, pela descarga de derivados de petróleo e de detergentes utilizados para dispensar minério e, o mais grave, pelo uso inadequado do mercúrio. O mercúrio é usado na amalgamação de partículas de ouro, etapa final do processo de beneficiamento do minério (SOUZA et al., 2008).

O mercúrio liberado pelo garimpo ou por outras fontes de poluição, quando no ambiente pode ser oxidado e metilado. No processo de metilação ocorre a transformação de compostos mercúricos em metilmercúrio $\left(\mathrm{CH}_{3} \mathrm{Hg}^{+}\right)$, a forma mais tóxica de mercúrio. Na maioria dos casos a metilação envolve bactérias. Os complexos orgânicos de mercúrio são biodisponíveis e podem ser acumulados pela biota aquática (VEIGA et al., 2002). A bioacumulação destes compostos faz com que as concentrações encontradas nos organismos vivos, animais e plantas, sejam superiores ao encontrado normalmente na natureza promovendo o transporte para vários níveis da cadeia alimentar (MOULIS \& THEVÉNOD, 2010).

Estima-se que na região de garimpo de Alta Floresta e Peixoto de Azevedo, no norte de Mato Grosso, a concentração de mercúrio em rios, córregos, lagos e no solo seja elevada. Segundo um levantamento, nos últimos 20 anos esta região recebeu de 150 a 200 toneladas de mercúrio (SOUZA et al., 2008).

Além da contaminação por mercúrio, a atividade garimpeira gera inúmeros outros impactos, como a derrubada da mata ciliar que propicia o assoreamento, a erosão e consequentemente a alteração da qualidade da água devido a contaminação por substâncias químicas diversas, uma vez que as margens dos rios ficam expostas. Com o aumento da sedimentação pode ocorrer o aumento da 
temperatura e diminuição dos níveis de oxigênio dissolvido na água, levando a alterações de ecossistemas (SOUZA et al., 2008).

Estudos de monitoramento ambiental têm mostrado efeitos danosos do emprego descontrolado de substâncias resultantes de atividades humanas no ambiente natural, tais como efluentes urbanos, industriais ou da agricultura, tendo levado a realização de avaliações cito e genotóxicas em vários ambientes aquáticos poluídos como mares, rios e lagos, utilizando, para isso, vários métodos (CIRCUNVINS et al., 2012).

Plantas superiores são reconhecidas como excelentes modelos para detectar mutágenos ambientais, sendo por isso usada com frequência em estudos de monitoramento. Dentre as espécies de plantas, a cebola (Allium cepa L.) tem sido usada para monitorar ambientes com suspeita de contaminação e para avaliar danos ao DNA, como anormalidades cromossômicas e distúrbios no ciclo mitótico (BRAGA \& LOPES, 2015). Diversos autores descrevem a indução de aberrações cromossômicas em células de A.cepa tratada com águas de rios, solos, efluentes industriais e extratos de plantas (GRIPPA et al., 2010; MARSIGLIA et al., 2011; GOMES et al., 2015; GALVÃO et al., 2015).

O Teste de $A$. cepa já foi utilizado para testar inúmeras substâncias, entre elas medicamentos, agrotóxicos, esgotos domésticos e industriais, águas de abastecimento humano, rios, lagos e mares, dentre outros. As vantagens de utilização deste bioensaio são: baixo custo, facilidade de execução e análise e o fato de poder ser realizado in vivo (BELCAVELLO et al., 2012; SILVA \& NASCIMENTO, 2013; COSTA et al., 2015).

Neste contexto, esse trabalho objetivou avaliar o potencial citotóxico e genotóxico de águas de cinco rios no município de Carlinda, MT, com histórico de atividades de garimpo, por meio do teste de Allium cepa.

\section{MATERIAL E MÉTODOS}

As coletas foram realizadas em cinco rios no município de Carlinda, no norte do Estado de Mato Grosso, com histórico de atividades garimpeiras: Rio Teles Pires, Rio Carlinda, Rio Buritis, Rio do sítio São José e Rio da fazenda Nacional (FIGURA 1).

Todos os pontos de coleta apresentam alterações causadas por atividades humanas. Os rios Buritis e Carlinda localizam-se próximo a uma rodovia que possui tráfego intenso de veículos e possuem assoreamento aparente. $O$ rio Carlinda serve de ponto de encontro nos finais de semana para pesca e recreação. Os rios da Fazenda Nacional e do Sítio São José não possuem mata ciliar e são rodeados por pastagem. Teles Pires é um dos principais rios da região e corta todo o estado de Mato Grosso, ainda é alvo do garimpo realizado por balsas, também é o maior em extensão e volume de água entre todos os pontos analisados. A tabela 1 indica as coordenadas geográficas dos pontos de coleta.

TABELA 1- Localização geográfica dos locais de coleta.

\begin{tabular}{|c|c|c|}
\hline Tratamentos & Latitude (S) & Longitude (W) \\
\hline Fazenda Nacional & 100' 36.36" & 55 49' 25.34" \\
\hline Buritis & $9^{\circ} 58^{\prime} 34.77^{\prime \prime}$ & $55^{\circ} 48^{\prime} 41.83^{\prime \prime}$ \\
\hline São José & 9 59'36.62" & $55^{\circ} 43^{\prime} 42.01^{\prime \prime}$ \\
\hline Carlinda & 9 57'02.22" & $55^{\circ} 52^{\prime} 28.74^{\prime \prime}$ \\
\hline Teles Pires & 10ㅇ 14' 19.91" & 554' 27.74” \\
\hline
\end{tabular}


As coletas foram realizadas no período de seca durante o mês de julho. Em cada rio foram coletados cinco litros de água em um único ponto na superfície, o material foi transportado para o laboratório de Genética Vegetal do Campus Universitário de Alta Floresta, UNEMAT. As amostras foram armazenadas em garrafas estéreis e mantidas a temperatura ambiente até o momento de realização dos testes.

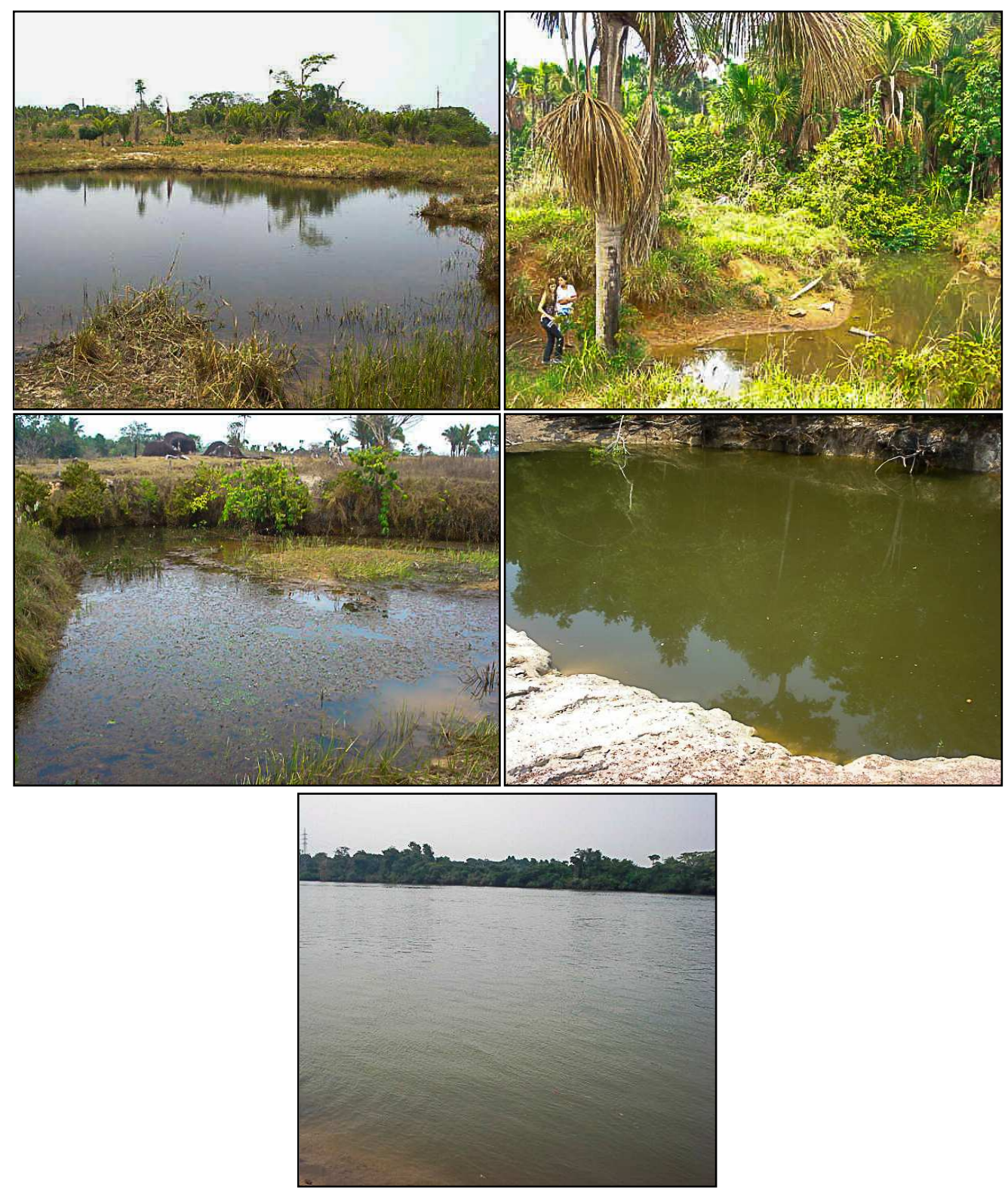

FIGURA 1. Locais de coleta. A) Fazenda Nacional; B) Rio Buritis; C) Sítio São José; D) Rio Carlinda; E) Rio Teles Pires.

Para cada ponto de coleta, foram selecionados dez bulbos de cebola de tamanho semelhante, ausência de traumas, deformidades naturais ou contaminação por fungos. $\mathrm{O}$ anel radicular foi lavado em água corrente e água destilada antes do início do teste. Os bulbos foram colocados em recipientes com $100 \mathrm{~mL}$ de cada amostra de água coletada e mantidos à temperatura ambiente para germinação. $\mathrm{A}$ água foi trocada a cada $24 \mathrm{~h}$. Como controle negativo utilizou-se água destilada.

Após $72 \mathrm{~h}$ de germinação dos bulbos em cada um dos tratamentos, as radículas foram coletadas e fixadas em Carnoy (3:1) por 24 horas em temperatura 
ambiente sendo em seguida transferidas para o álcool $70 \%$ e mantidas sob refrigeração de $4^{\circ} \mathrm{C}$ até a utilização.

Para montagem das lâminas as radículas foram cuidadosamente lavadas em água destilada por cinco minutos, posteriormente submetidas à hidrólise ácida em solução de HCL $5 \mathrm{~N}$ por 15 minutos e novamente recolocadas na água destilada por mais cinco minutos. O material a ser analisado foi colocado sobre a lâmina com uma pinça e com o auxílio de um bisturi foi seccionada a região meristemática, o restante do material foi descartado, deixando sobre a lâmina somente o meristema apical. Posteriormente acrescentou-se uma gota de carmim acético (2\%), em seguida colocou-se a lamínula, seguida de uma leve maceração com o bastão de vidro, através da técnica de esmagamento (GUERRA \& SOUZA, 2002) e de acordo com protocolo de BARBÉRIO et al. (2011).

O material foi observado em microscópio óptico binocular com magnitude de 400X. Foram preparadas quatro lâminas para cada tratamento, em cada uma das lâminas foram contadas 500 células, totalizando 2.000 células por tratamento. Os efeitos citotóxicos e genotóxicos foram avaliados através da análise das divisões celulares, índice mitótico (IM) e aberrações cromossômicas (AC) segundo a equação proposta por PIRES et al. (2001).

Os dados foram submetidos à análise de variância e as médias comparadas pelo teste de Tukey $(p=0,05)$. Todas as análises foram realizadas pelo programa estatístico SISVAR 5.0 (FERREIRA, 2003).

\section{RESULTADOS E DISCUSSÃO}

Os resultados da tabela 2 demonstram que o maior Índice Mitótico (IM) entre os tratamentos ocorreu no rio Buritis $(28,65 \%)$ e o menor no controle negativo $(10,65 \%)$. O tratamento que se aproximou mais do controle negativo foi o do rio Teles Pires (13,45\%). Se comparado com o controle negativo, todos os tratamentos estimularam o IM. DÜSMAN et al., (2012) em estudos nos rios da área urbana de Maringá-PR também verificaram o aumento no índice mitótico dos tratamentos quando comparado ao controle. Para MASCHIO (2009) os níveis de citotoxicidade de um composto testado podem ser determinados pelo aumento ou decréscimo do índice mitótico. De acordo com GRIPPA et al., (2010) o decréscimo no índice mitótico pode inferir a presença de substâncias citotóxicas com capacidade mutagênica, já o aumento no índice mitótico, como o encontrado neste estudo, indica que houve uma indução da divisão celular, a qual também pode ser considerada prejudicial às células, uma vez que a proliferação descontrolada pode levar a formação de tumores nos seres vivos.

Todas as áreas analisadas foram alvo de garimpo, e receberam cargas de mercúrio. De acordo com JESUS \& CARVALHO (2008) o mercúrio e seus compostos são ativos quimicamente e, dependendo da concentração podem alterar atividades celulares. O Índice Mitótico de $A$. cepa tratadas com a água do rio Teles Pires não diferiu estatisticamente do controle e foi o menor dentre os cinco rios analisados (Tabela 2), indicando que as induções do IM que ocorrem nos demais rios não ocorrem no rio Teles Pires. Este resultado pode ser justificado pelo fato do rio Teles Pires ser o maior, tanto em profundidade, quanto em largura e volume de água, possuindo também uma mata ciliar maior e mais preservada (Figura 1). De acordo com COSTA et al., (2015) a ocorrência de chuvas e os efeitos sobre a profundidade total do rio, bem como, a possibilidade de arraste de solos alterando a composição físico-química da água também influenciam no efeito citotóxico das 
águas. Ou seja, as águas dos rios que apresentaram maior IM podem estar sendo influenciados por esses fatores, enquanto o rio Teles Pires não.

TABELA 2. Resultados dos percentuais médios de Índice Mitótico (IM) em raízes de $A$. cepa submetidas aos diferentes tratamentos.

\begin{tabular}{ccc}
\hline Tratamentos & $\begin{array}{c}\text { No de células } \\
\text { analisadas }\end{array}$ & IM (\%) \\
\hline Teles Pires & 2000 & $13,45 \mathrm{~B}$ \\
São José & 2000 & $26,90 \mathrm{~A}$ \\
Buritis & 2000 & $28,65 \mathrm{~A}$ \\
Nacional & 2000 & $20,10 \mathrm{AB}$ \\
Carlinda & 2000 & $23,80 \mathrm{~A}$ \\
Controle Negativo & 2000 & $10,65 \mathrm{~B}$ \\
\hline Médias seguidas pelas mesmas letras maiúsculas não diferem \\
estatisticamente entre si a 5\% de probabilidade pelo teste de Tukey.
\end{tabular}

Em trabalho realizado com as águas superficiais do Ribeirão Atlântico em Mandaguaçu-PR, CIRCUNVINS et al., (2012) também encontraram aumento no índice mitótico em um dos tratamentos, esse resultado foi justificado por a área ser cercada de atividades agrícolas, demonstrando que a vulnerabilidade ambiental está concentrada nos processos erosivos e escoamentos superficiais, devido ao uso indevido das áreas ripárias. O escoamento superficial de componentes orgânicos provenientes da adubação e manejo da área para o rio pode ter estimulado a divisão celular mitótica nas células meristemáticas de $A$. cepa. Como os locais que apresentaram maior IM neste estudo, localizam-se próximos a áreas com atividade agropecuária e possuem mata ciliar alterada ou ausente pode-se inferir que essa condição ambiental também interferiu no resultado encontrado.

Foram observados dois tipos diferentes de anormalidades cromossômicas: cromossomos isolados (na prófase, metáfase, anáfase e telófase) e ponte de cromatina (na anáfase), conforme apresentado na Tabela 3. Em um estudo realizado em Alta Floresta-MT, município vizinho a Carlinda-MT, GALVÃO et al., (2015) também encontraram cromossomos isolados, analisando os esgotos de laticínio, frigorífico, estação de tratamento municipal e as águas de um córrego influenciado por esses esgotos.

TABELA 3. Número Total de Anormalidades Cromossômicas (NTAC), percentual de Anormalidades Cromossômicas (\%AC) e frequência de cada tipo de alteração nas raízes de $A$. cepa, nos diferentes tratamentos realizados.

\begin{tabular}{cccccccc}
\hline Tratamentos & NTAC & AC & PC-A (\%) & Cl-P (\%) & Cl-M (\%) & Cl-A (\%) & Cl-T (\%) \\
\hline Teles Pires & 1 & 0,05 & - & - & - & 100 & - \\
São José & 3 & 0,15 & 33,3 & - & 66,6 & - & - \\
Buritis & 3 & 0,15 & - & - & 33,3 & 66,6 & - \\
Nacional & 20 & 1,0 & - & - & 30 & 45 & 25 \\
Carlinda & 22 & 1,1 & 31,8 & 4,5 & 9,09 & 50 & 9,09 \\
Controle (-) & 8 & 0,4 & 12,5 & - & 25 & 62,5 & - \\
\hline
\end{tabular}

$\mathrm{PC}-\mathrm{A}=$ Ponte de Cromatina na Anáfase $; \mathrm{Cl}-\mathrm{P}=$ Cromossomo Isolado na Prófase; $\mathrm{Cl}-\mathrm{M}=$ Cromossomo Isolado na Metáfase; $\mathrm{Cl}-\mathrm{A}=$ Cromossomo Isolado na Anáfase; $\mathrm{Cl}-\mathrm{T}=$ Cromossomo Isolado na Telófase. 
$\mathrm{Na}$ anáfase foi observado o maior percentual de anormalidades cromossômicas. SANTOS (2013) em estudo com extrato de pó de guaraná, também observou que as aberrações cromossômicas foram vistas com maior frequência nas anáfases com pontes de cromatina e cromossomo isolado, o que pode ser justificado devido na fase da anáfase existir a possibilidade de ocorrência dos dois tipos de anomalias. A anormalidade de cromossomo isolado incidiu em maior percentual $(81,54 \%$ ) em relação à anormalidade ponte de cromatina (Figura 2). Esse resultado também foi encontrado por GALVÃO et al., (2015), segundo os autores isso ocorre devido a anomalia ocorrer em quase todas as fases mitóticas.

O primeiro mecanismo de ação dos agentes genotóxicos é promover lesões no DNA (oxidação e dimerização de bases, entre outras) que podem ter três destinos: reparo, alterações irreversíveis e morte celular (MAJER et al., 2005). As pontes cromossômicas encontradas neste estudo são exemplos desse tipo de mecanismo e podem indicar a presença de substâncias clastogênicas (indutoras de quebras) nas amostras testadas, conforme descrito por OLIVEIRA et al., (2011) em estudo com as águas do rio Paraíba do Sul em Tremembé-SP, utilizando o teste $A$. cepa.

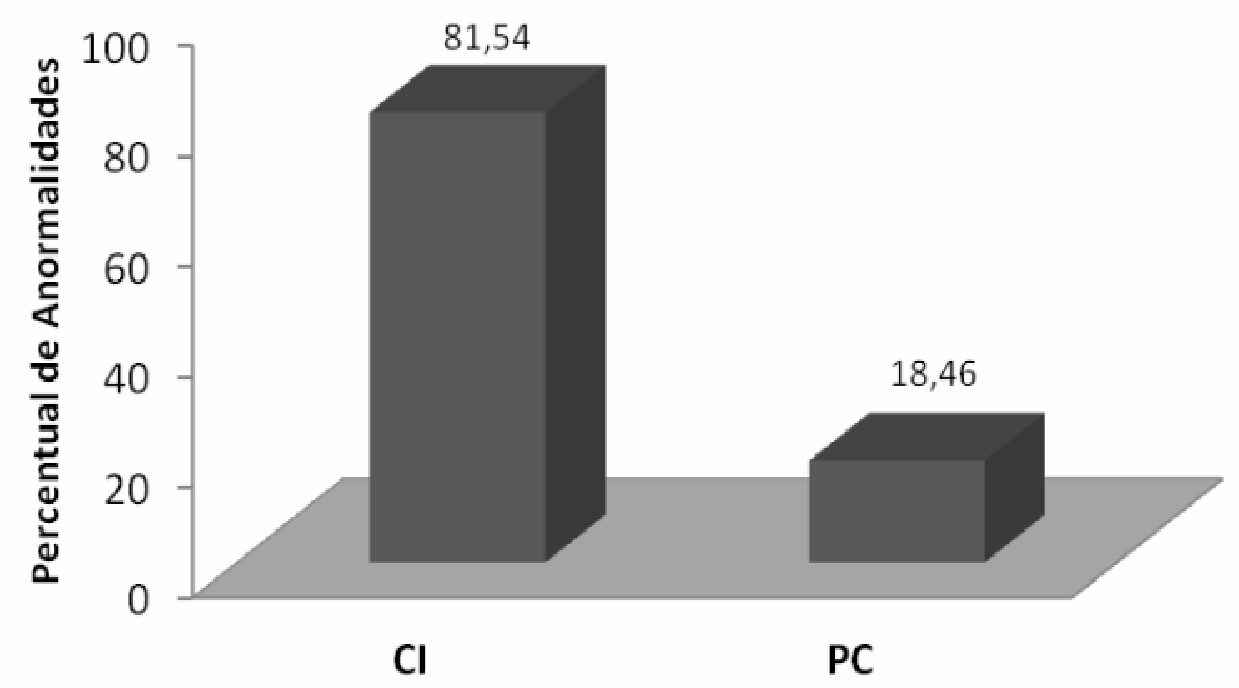

FIGURA 2. Percentual de anormalidades em células meristemáticas de Allium cepa, submetidas a diferentes tratamentos. $\mathrm{Cl}=$ Cromossomo Isolado; $\mathrm{PC}=$ Ponte de Cromatina.

Os locais de coleta são bastante degradados (Figura 1), observando-se neles assoreamento, erosão e pouca ou nenhuma mata ciliar, exceto no rio Teles Pires que apresentou IM e AC menor que os demais pontos de coleta. $O$ rio da fazenda Nacional que apresentou uma das maiores taxas de anormalidades cromossômicas dentre os tratamentos e um índice mitótico de 20,10\%, localiza-se em meio a uma pastagem e não possui mata ciliar, e pode estar sendo influenciado por sedimentação ou arraste de substâncias químicas provenientes do manejo da pastagem. Nas proximidades do rio Carlinda que também apresentou índice de anormalidades celulares e IM (23,80\%) maiores quando comparado ao controle, 
existe grande tráfego de automóveis, além disso, é um ponto de pesca e de lazer nos finais se semana o que contribui para a deposição de resíduos dentre eles compostos orgânicos que, de acordo com CIRCUNVINS et al., (2012), se somados aos resíduos carregados para o leito do rio podem servir de fonte de nutrientes para indução da divisão celular.

As águas do rio Buritis, que revelou maior IM, não apresentou alto índice de anormalidades cromossômicas, indicando que o rio possui potencial citotóxico, mas não possui potencial genotóxico. O mesmo ocorreu com as águas do rio do Sítio São José. De acordo com FISKESJÖ (1985) estudos com $A$. cepa demostram que nem sempre a toxicidade está correlacionada com a genotoxicidade, porque alterações relacionadas com o crescimento da raiz e IM são parâmetros indicativos de citotoxicidade. Por outro lado, alterações como anomalias cromossômicas (micronúcleos, pontes cromossômicas, entre outras), indicam genotoxicidade.

A água do rio Teles Pires não apresentou potencial citotóxico nem genotóxico visto que o IM foi próximo ao do controle e o índice de anormalidades cromossômicas apresentou-se bem abaixo se comparado com os demais tratamentos.

\section{CONCLUSÃO}

As águas dos rios São José, Nacional, Buritis, e Carlinda possuem potencial citotóxico, enquanto as águas do rio Teles Pires não, pois o IM revelado por suas águas em $A$. cepa não diferiu estatisticamente do controle. Quanto à genotoxidade as águas dos rios Nacional e Carlinda apresentaram maior frequência de anormalidades cromossômicas em células meristemáticas da cebola, em relação as águas dos demais rios estudados.

\section{REFERÊNCIAS}

BARBÉRIO, A.; VOLTOLINI, J. C.; MELLO, M. L. S. Standardization of bulb and root sample sizes for the Allium cepa test. Ecotoxicology, v. 20, n. 4, p. 927-935, 2011.

BELCAVELLO, L.; CUNHA, M. R. H.; ANDRADE, M. A.; BATITUCCI, M. C. P. Citotoxicidade e danos ao DNA induzidos pelo extrato de Zornia diphylla, uma planta medicinal. Natureza on line. v. 10, n. 3, p. 140-145, 2012.

BRAGA, J. R. M.; LOPES, D. M. Citotoxicidade e genotoxicidade da água do rio Subaé (Humildes, Bahia, Brasil) usando Allium cepa L. como bioindicador. Revista Ambiente \& Água. v. 10, n. 1, Taubaté, Jan./Mar., 2015.

CIRCUNVIS, B. C.; HECK, M. C.; VICENTINI, V. E. Investigação do potencial citotóxico das águas superficiais do Ribeirão Atlântico (Madaguaçu-PR) em Allium cepa L. Revista Saúde e Biologia. v.7, n.3, p.7-14, Set./Dez., 2012.

COSTA, A. C.; DOMINGUES, G.; DÜSMAN, E.; ALMEIDA, I. V.; VICENTINI, V. E. P. Citotoxicidade das águas do Rio do Peixe (São Paulo-Brasil), em células meristemáticas de raiz de Allium cepa L. Bioscience Journal. Uberlândia, v. 31, n. 1, p. 248-258, Jan./Fev., 2015.

CUNHA, J. M. P.; ALMEIDA, G. M. R.; RAQUEL, F. Migração e Transformações Produtivas na Fronteira: o caso de Mato Grosso. In: XIII Encontro da Associação 
Brasileira de Estudos Populacionais, 2002, Ouro Preto. Anais... Ouro Preto: ABEP, 2002.

DÜSMAN, E.; GONÇALVES, L. A.; REUSING, A. F.; MARTIN, P. G.; MARIUCCI, R. G.; VICENTINI, V. E. P. Cytotoxic potential of waters of the streams Mandacaru, Maringá, Miosótis and Nazareth in the urban area of Maringá, Paraná State, Brazil. Acta Scientiarum. v. 34, n. 3, p. 311-318, Jul./Set., 2012

FERREIRA, D.F. SISVAR 5.0 Sistema de Análises Estatísticas. Lavras: UFLA, 2003.

FISKESJO, G. The Allium test. As a standard in environmental monitoring. Hereditas, 102, p. 99-112, 1985.

GALVÃO, M.; MIRANDA, D. P.; COSTA, G. M.; SILVA, A. B. da; KARSBURG, I. V. Índice de genotoxidade por Allium cepa no teste de bioindicador em águas poluídas por dejetos químicos no município de Alta Floresta. Enciclopédia Biosfera, Centro Científico Conhecer - Goiânia, v.11, n.21, p. 2373-2383, 2015.

GOMES, J. V.; TEIXEIRA, J. T. S.; LIMA, V. M.; BORBA, H. R.; Induction of cytotoxic and genotoxic effects of Guandu River waters in the Allium cepa system. Revista Ambiente \& Água, v. 10, n. 1, Taubaté, Jan./Mar., 2015

GRIPPA, G. A.; MOROZESK, M.; NATI, N.; MATSUMOTO, S. T. Estudo genotóxico do surfactante Tween 80 em Allium cepa. Revista Brasileira de Toxicologia, v. 23, n.1-2, p. 11-16, 2010.

GUERRA, M.; SOUZA, S. M. J. Como observar cromossomos: um guia de técnicas em citogenética vegetal, animal, e humana. Fundação de Pesquisas Científicas de Ribeirão Preto, Ribeirão Preto, 2002.

JESUS, T. B.; CARVALHO, C. E. V. Utilização de biomarcadores em peixes como ferramenta para avaliação de contaminação ambiental por mercúrio $(\mathrm{Hg})$. Oecologia Brasiliensis. v. 12, n. 4, p: 680-693, 2008.

MASCHIO, L. R. Avaliação do potencial citotóxico, genotóxico e mutagênico das águas do Rio Preto na área de influência da região de São José Do Rio Preto/SP. 2009. 208 f. Tese (Doutorado em Genética) Universidade Estadual Paulista, São José do Rio Preto.

MAJER, B. J.; GRUMMT, T.; UHL, M.; KNASMÜLLER, S. Use of plant bioassays for the detection of genotoxins in the aquatic environment. Acta Hydrochimica Hydrobiologica, Weinheim, v. 33, n. 1, p. 45-55, 2005.

MARSIGLIA. J. D. C.; LOSS, A. C. C.; STANGE, V. S.; BELCAVELLO, L.; LUZ, A. C.; BATITUCCI, M. C. P. Avaliação dos efeitos tóxico, citotóxico e genotóxico do extrato bruto hidroalcoólico de Solanum cordifolium Dunal e Solanum torvum Sw. Natureza on line. v. 9, n. 1, p. 30-34, 2011.

MOULIS, J.M.; THEVÉNOD, F. New perspectives in cadmium toxicity: an introduction. Biometals. v. 23, p. 763-768, 2010. 
OLIVEIRA, L. M; VOLTOLINI, J. C.; BARBÉRIO, A. Potencial mutagênico dos poluentes na água do rio Paraíba do Sul em Tremembé, SP, Brasil, utilizando o teste Allium cepa. Revista Ambiente \& Água - An Interdisciplinary Journal of Applied Science. v. 6, n. 1, p. 90-103, 2011.

PIRES, N. D. M.; SOUZA, I. R. P.; PRATES, H. T.; FARIA, T. C. L. D.; PEREIRA FILHO, I. A.; MAGALHÃES, P. C. Efeito do extrato aquoso de leucena sobre o desenvolvimento, índice mitótico e atividade da peroxidase em plântulas de milho. Revista Brasileira de Fisiologia Vegetal, v.13, n.1, p. 55-65, 2001.

SANTOS, A. L. dos.; Sistema teste Allium cepa como bioindicador de genotoxicidade e citotoxicidade do extrato aquoso do pó da semente do guaraná. 2013, 35 f. Monografia (Licenciatura em Ciências Biológicas), Universidade do Estado de Mato Grosso, Alta Floresta.

SILVA, C. C.; NASCIMENTO, F. M. Citogenotoxicidade de amostras de água do Rio Tietê em células meristemáticas radiculares de Allium cepa. Atas de Saúde Ambiental. v. 1, n. 1, p. 26-35, Set./dez., 2013.

SOUZA, L. C. D.; CARVALHO, M. A. C.; CORRÊA, B. S.; SILVA, M. P. Consequências da atividade garimpeira nas margens do Rio Peixoto de Azevedo no perímetro urbano do município de Peixoto de Azevedo - MT. Revista de Biologia e Ciências da Terra. v. 8, n. 2, p. 220-231, 2008.

VEIGA, M. M.; SILVA, A. R. B.; HINTON, J. J. Garimpo de ouro na Amazônia: Aspectos Tecnológicos, Ambientais e Sociais. In: TRINDADE, R. B. E.; BARBOSA FILHO, O. Extração de Ouro - Princípios, Tecnologia e Meio Ambiente. Rio de Janeiro, CETEM, p. 267-295, 2002. 